\title{
Interactive comment on "Complementary principle of evaporation: From original linear relationship to generalized nonlinear functions" by Songjun Han and Fuqiang Tian
}

\section{Anonymous Referee \#1}

Received and published: 31 December 2019

The paper summarizes the history of the complementary principle of evaporation, with an emphasis on how the symmetric linear complementary relationship develops to generalized nonlinear functions. In general, I enjoyed reading such a review on the CR, which was widely used to estimate ET over different spatial and/or temporal scales.

My main comment is there are still some works worth being discussed, though this review is overall complete: 1) The perspective of Lhomme and Guilioni $(2006,2010)$ which relates potential evaporation to surface resistance. 2) Aminzadeh et al. (2016)'s CR with Ep defined by a surface temperature

Also, there are a few latest CR studies in 2019 that are highly relevant to the submitted 
manuscript, e.g., Anayah \& Kaluarachchi (2019) and Brutsaert et al. (2019). Could the authors discussed a little bit?

Specific Comments: Line 19: Is the boundary condition here specified to the wet environment?

Line 40: Recent publications using GCR in 2019 for estimating evaporation should be added here.

Line 87: "while" should be replaced by "whereas"?

Line 107: the "realistic" is compared to the former model. I think adding "more" here may be better.

Line 110: "wss"??

Line 167: "The asymmetric CR is widely used", please revised this sentence

Line 179: More statements on the asymmetric CR should be added, including the negative relationship between E/Epo and Epa/Epo was treated as an extension of the original $\mathrm{CR}$, and the validation in several locations.

Line 246: "Han and Tian (2018) further validated the sigmoid feature": Please state the work more detailed because there are still controversies on it.

Line 270: What is the essential difference between B15 and H12? Is "B15 inherits all three types of evaporation dated from the original CR"? Please rearrange these sentences.

Line 304: The varying characteristics of the PT coefficient should be introduced here Line 359: Brutsaert's recent work by using $\mathrm{c}=0$ and varying PT coefficient should be added. Check Brutsaert et al. (2019). The Conclusion part could be improved. I wonder are there any outlooks for future studies on CR could be summarized using a few sentences here?

Printer-friendly version

Discussion paper 
Reference: Aminzadeh, M., Roderick, M. L., \& Or, D. (2016). A generalized complementary relationship between actual and potential evaporation defined by a reference surface temperature. Water Resources Research, 52(1), 385-406. doi:10.1002/2015wr017969 Anayah, F. M., \& Kaluarachchi, J. J. (2019). Estimating Global Distribution of Evapotranspiration and Water Balance Using Complementary Methods. Atmosphere-Ocean, 57(4), 279-294. doi:10.1080/07055900.2019.1656052 Brutsaert, W., Cheng, L., \& Zhang, L. (2019). Spatial Distribution of Global Landscape Evaporation in the Early Twenty First Century by Means of a Generalized Complementary Approach. Journal of Hydrometeorology. doi:10.1175/jhm-d-19-0208.1 Lhomme, J. P., \& Guilioni, L. (2006). Comments on some articles about the complementary relationship. Journal of Hydrology, 323, 1-3. Lhomme, J. P., \& Guilioni, L. (2010). On the link between potential evaporation and regional evaporation from a CBL perspective. Theoretical and Applied Climatology, 101(1), 143-147.

Interactive comment on Hydrol. Earth Syst. Sci. Discuss., https://doi.org/10.5194/hess-2019545, 2019. 